\title{
Perdas reprodutivas associadas com infecção por Toxoplasma gondii em caprinos no sul do Brasil ${ }^{1}$
}

\author{
Caroline A. Pescador ${ }^{2}$, Eduardo C. Oliveira² ${ }^{2}$ Pedro M.O. Pedroso² ${ }^{2}$, Paulo M. \\ Bandarra $^{2}$, Líria H. Okuda ${ }^{3}$, Luís G. Corbellini ${ }^{4}$ e David Driemeier ${ }^{2}$
}

\begin{abstract}
Pescador C.A., Oliveira E.C., Pedroso P.M.O., Bandarra P.M., Okuda L.H., Corbellini L.G. \& Driemeier D. 2007. [Reproductive losses linked to Toxoplasma gondii infection in goats in southern Brazil.] Perdas reprodutivas associadas com infecção por Toxoplasma gondii em caprinos no sul do Brasil. Pesquisa Veterinária Brasileira 27(4):167-171. Departamento de Patologia Clínica Veterinária, Faculdade de Veterinária, Universidade Federal do Rio Grande do Sul, Av. Bento Gonçalves 9090, Porto Alegre, RS 91540-000, Brazil. E-mail: davetpat@ufrgs.br

Toxoplasma gondii was implicated with reproductive losses in a goat herd in Rio Grande do Sul, Brazil. Gross changes were present in 2 out of 6 fetuses/offsprings submitted for diagnosis and included enlarged, pale mesenteric lymph nodes, and edematous, mottled red and tan lungs. Microscopic changes were observed in most fetuses and were especially characterized by lymphoplasmacytic infiltration in the brain and lungs. Other histological changes included lymphoplasmacytic interstitial nephritis, necrotizing lymphadenitis and periportal lymphoplasmacytic cell infiltrates. While bacteriological and direct immunofluorescent antibody tests for Leptospira sp. were negative in samples from all cases, immunohistochemical and PCR procedures for Toxoplasma gondii reacted positively in most of them. Antibody titles against $T$. gondii varying from 1:512 to 1:2048 were detected in serum samples from the mother goats of these aborted (1), stillborn (3) or dead newborn (2) kids. This paper describes the clinical, pathological, serological, molecular and immunohistochemical findings of a Toxoplasma gondiiinfected goat flock.
\end{abstract}

INDEX TERMS: Abortion, goat, reproductive losses, stillborn, Toxoplasma gondii.

RESUMO.- Infecção por Toxoplasma gondii foi associada com perdas reprodutivas em um rebanho caprino no Rio Grande do Sul, Brasil. Lesões macroscópicas foram observadas em dois de seis produtos caprinos enviados para diagnóstico e incluíram linfonodos mesentéricos pálidos e aumentados e pulmões com consistência firme e áreas claras intercaladas com vermelhas. Lesões histológicas, especialmente caracterizadas por infiltrados linfoplasmocitários no cérebro e pulmões, foram observadas em todos os fetos. Nefrite intersticial linfoplasmoci-

\footnotetext{
${ }^{1}$ Recebido em 7 de outubro de 2006.

Aceito para publicação em 12 de dezembro de 2006.

${ }^{2}$ Departamento de Patologia Clínica Veterinária, Faculdade de Veterinária, Universidade Federal do Rio Grande do Sul (UFRGS), Av. Bento Gonçalves 9090, Porto Alegre, RS 91540-000, Brasil. *Autor para correspondência: davetpat@ufrgs.br

${ }^{3}$ Laboratório de Viroses de Bovídeos, Instituto Biológico, Av. Conselheiro Rodrigues Alves 1252, São Paulo, SP 04014-002, Brasil.E-mail: okuda@biologico.sp.gov.br

${ }^{4}$ Departamento de Medicina Veterinária Preventiva, Faculdade de Veterinária, UFRGS.
}

tária, linfadenite necrosante e hepatite periportal linfoplasmocitária também foram observadas. Enquanto tanto o exame bacteriológico quanto o teste de imunofluorescência direta para Leptospira sp. foram negativos em todos os casos, a PCR e a imunoistoquímica resultaram positivamente para $T$. gondii em quase todas as amostras testadas. Anticorpos anti-T.gondii, em titulações de 1:512 a 1:2048, foram detectados nas amostras de soro sanguííneo das cabras que pariram natimortos (3), abortaram (1) ou cujos neonatos morreram (2). Este trabalho descreve os achados clínicos, patológicos, sorológicos, imunoistoquímicos e de PCR observados em um rebanho caprino infectado por $T$. gondii.

TERMOS DE INDEXAÇÃO: Aborto, caprino, natimorto, perdas reprodutivas, Toxoplasma gondii.

\section{INTRODUÇÃO}

Toxoplasma gondii é um coccídeo intracelular obrigatório com distribuição mundial e capacidade de causar doença em humanos, pequenos ruminantes e vários outros mamíferos (Massala 
et al. 2003). A toxoplasmose tem sido identificada como uma das maiores causas de problemas reprodutivos em ovinos e caprinos na Grã-Bretanha, Noruega, Austrália, Nova Zelândia, nos EUA e no Uruguai, assim como em outros países (Blewett \& Watson 1984, Dubey \& Beattie 1988, Skjerve et al. 1998, Freyre et al. 1999, Borde et al. 2006). No Brasil, estudos realizados especialmente em pequenos ruminantes têm detectado prevalências de 28,9-92,4\% de anticorpos anti-T.gondii nos rebanhos (Amaral et al. 1978, Chiari et al. 1987, Sella et al. 1994, Gondim et al. 1999, Silva et al. 2003, Maciel \& Araújo 2004). A infeç̧ão por $T$. gondii pode causar reabsorção fetal, aborto em diferentes idades gestacionais, mumificação fetal, natimortalidade ou mortalidade perinatal (Blewett 1983). A história clínica, a detecção de anticorpos específicos no rebanho e a observação de lesões histológicas características na placenta e no cérebro de fetos abortados ou natimortos, bem como a utilização das técnicas de imunoistoquímica e PCR em amostras de tecidos fetais (Dubey et al. 1987, Buxton 1991, Owen et al. 1998, Hurtado et al. 2001) fundamentam o diagnóstico de toxoplasmose. Este trabalho descreve os achados clínicos, patológicos, sorológicos, moleculares e imunoistoquímicos observados em um rebanho caprino infectado por $T$. gondii.

\section{MATERIAL E MÉTODOS}

Em outubro de 2005, três neonatos (mortos), três natimortos e um abortado (mumificado) caprinos da raça Boer foram encaminhados ao Setor de Patologia Veterinária (SPV), UFRGS, para diagnóstico. Fragmentos de diversos órgãos foram coletados durante a necropsia, fixados em formalina tamponada a $10 \%$, processados pelos métodos convencionais para histologia e corados com hematoxilina-eosina. Impressões de secções de rim foram testadas pela imunofluorescência direta para Leptospira sp com anticorpo comercial multivalente na diluição de 1:20 (Miller et al. 1989). Fragmentos de fígado, pulmão e conteúdo abomasal foram coletados para bacteriologia (aeróbio e Brucella sp). $\mathrm{O}$ cultivo aeróbio foi realizado em ágar sangue ovino (5\%) e a tentativa de isolamento de Brucella sp em meio-base de ágar sangue (Alton et al. 1988, Timoney et al. 1988) acrescido com 5\% de sangue ovino e antibióticos. Fragmentos de cérebro foram submetidos aos testes imunoistoquímicos com anticorpos policlonais anti-T.gondii e anti-N.caninum na diluição de 1:1000. DAB foi o cromógeno. Controles positivos foram inseridos simultaneamente com as lâminas testadas. Amostras de cérebro, fígado e coração, coletadas à necropsia em ependorfs e conservadas a $-20^{\circ} \mathrm{C}$, foram submetidas à técnica de nested-PCR para T. gondii (Lin et al. 2000) no Laboratório de Viroses de Bovídeos, Instituto Biológico, São Paulo. A extração do DNA foi obtida por Trizol LS (Invitrogen $\left.{ }^{\circledR}\right)$. Os primers utilizados foram TOXO-1; 5'-GGAACTGCATCCGTTCATGAG-3' e primer reverso TOXO 2;5'- TCTTTAAAGCGTTCGTGGTC-3'); a leitura foi feita em gel de agarose 2\%. Amostras de soro sanguíneo das mães dos produtos enviados foram testadas para Toxoplasma gondii (Hemaglutinação indireta) e vírus da Artrite e Encefalite Caprina (CAEV) pela técnica de Agar Gel Imunodifusão.

\section{RESULTADOS}

O rebanho possuía, em 2005, um total de 240 cabras da raça Boer, sendo 180 fêmeas e 60 machos. Os problemas reprodutivos estavam sendo observados por mais de um ano e não havia nenhum registro de vacinação no rebanho, apenas de dosificações com anti-helmínticos. De 70 fêmeas prenhas em 2005, 20 abortaram (três mumificados), tiveram produtos natimortos ou que morreram logo após o parto. Seis desses 20 casos foram enviados ao SPV para diagnóstico. Alterações macroscópicas foram vistas somente em dois animais e se caracterizaram por linfonodos mesentéricos pálidos e aumentados (Caso 1) e pulmões com edema e áreas avermelhadas intercaladas com áreas claras (Casos 1 e 5). Na microscopia, as alterações no sistema nervoso central foram encefalite não supurativa multifocal moderada com necrose (Fig,1), (Casos 1, 3 e 4), meningoencefalite não supurativa multifocal moderada associada a meningite não supurativa focalmente extensa e acentuada (Caso 5), gliose multifocal leve (Caso 6) e mielite não supurativa multifocal moderada (Caso 2). Dois padrões de pneumonia foram observados: pneumonia intersticial piogranulomatosa difusa moderada com presença de células gigantes (Caso 1) e pneumonia intersticial mononuclear com área de necrose (Fig.2) difusa moderada (Casos 3 e 4). No Caso 1, havia hepatite mononuclear periportal leve, miocardite mononuclear leve, nefrite intersticial mononuclear multifocal moderada e linfadenite

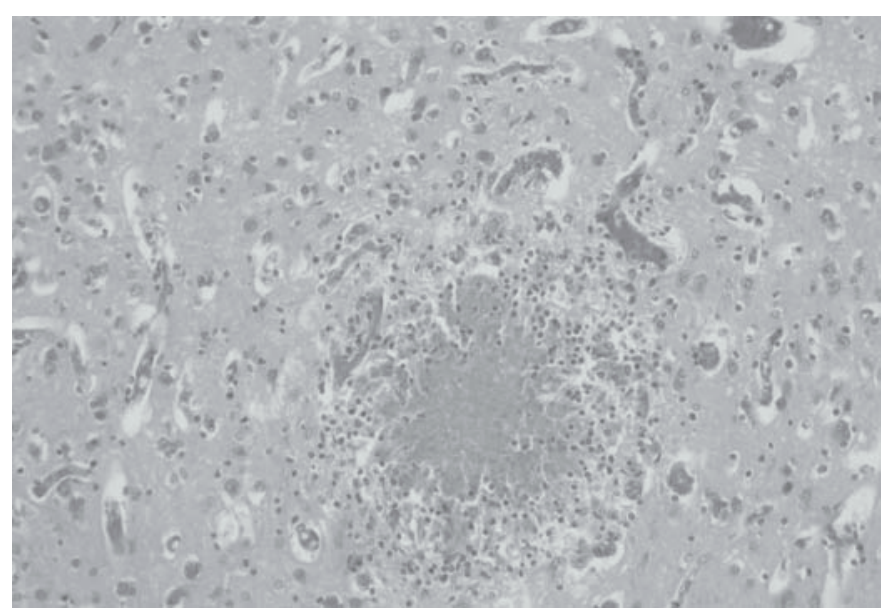

Fig.1. Encefalite necrosante não supurativa focal acentuada (Caso 3). HE, obj. 20.

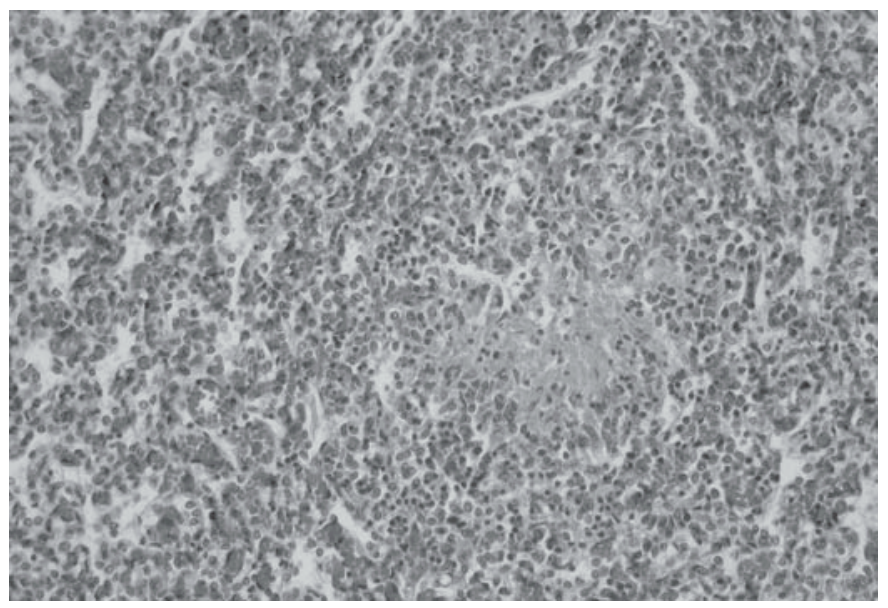

Fig.2. Pneumonia intersticial mononuclear associada à necrose focal (Caso 4). HE, obj.20. 

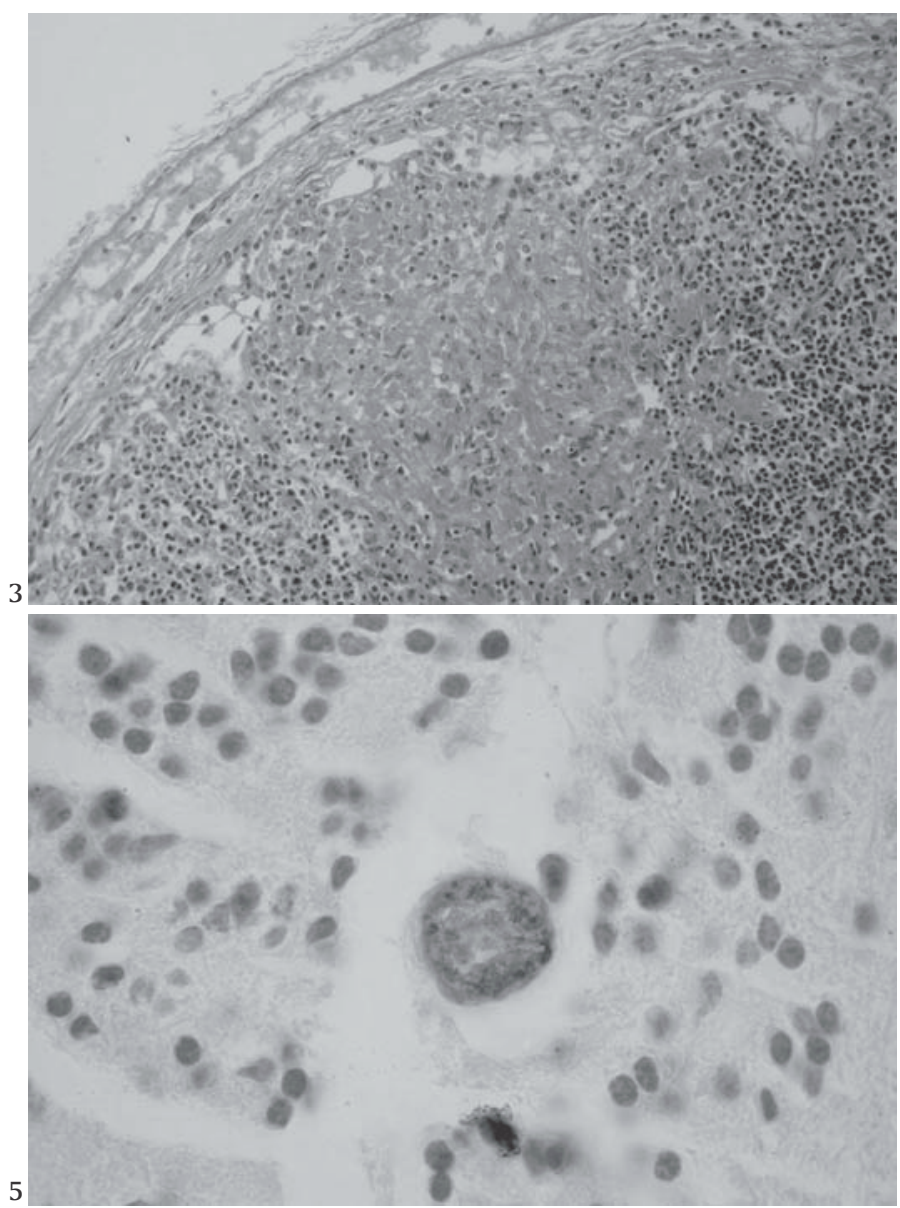

granulomatosa multifocal acentuada (Fig.3 e 4). A imunoistoquímica para T. gondii foi positiva somente no Caso 1 , em cujo foco de encefalite foram observados grupos de taquizoítos e cistos (Fig.5). Todas as amostras testadas na imunoistoquímica anti- $N$. caninum foram negativas. Exceto pelo caso 1 (que não

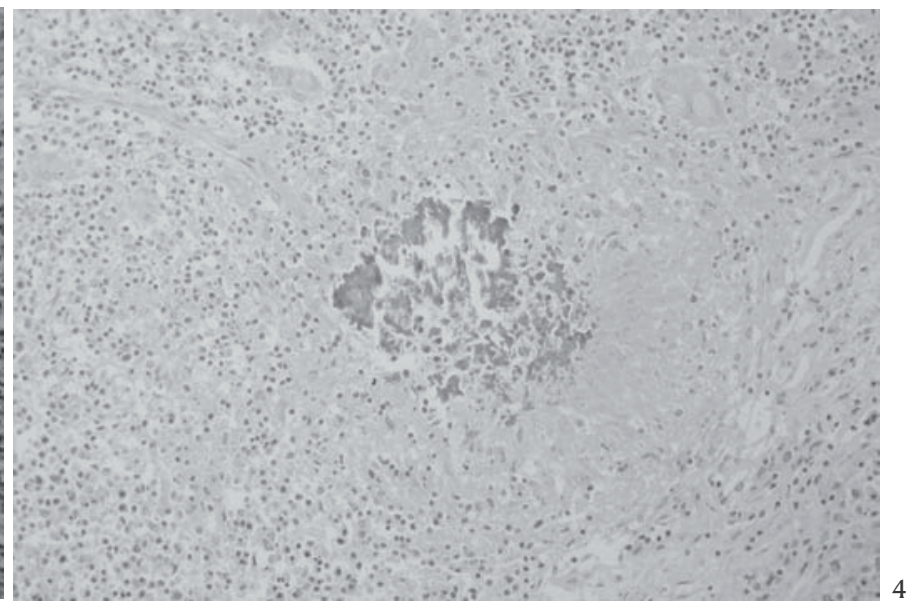

Fig.3. Linfadenite granulomatosa focal subcapsular (Caso 1). HE, obj.40.

Fig.4. Linfadenite granulomatosa com necrose caseosa e mineralização (Caso 1 ). HE, obj.20

Fig.5. Imunoistoquímica anti-Toxoplasma gondii em cérebro de feto caprino. Presença de cisto marcado com DAB (Caso 1). Obj.100.

foi testado), os demais foram positivos no teste de nested-PCR para $T$. gondii. O produto de amplificação esperado foi $98 \mathrm{pb}$. No Quadro 1 está apresentada a síntese dos achados histopatológicos, imunoistoquímicos e de nested-PCR bem como a sorologia por hemaglutinação indireta para $T$. gondii das amostras das mães dos fetos enviados. A imunodifusão para CAEV foi negativa nas amostras dos seis casos, assim como a bacteriologia e a imunofluorescência direta para Leptospira sp.

Quadro 1. Achados clínicos, histopatológicos, imunoistoquímicos e moleculares em seis fetos caprinos natimortos, neonatos ou abortados e títulos sorológicos anti-Toxoplasma gondii das respectivas mães

\begin{tabular}{|c|c|c|c|c|c|c|c|}
\hline \multirow[t]{2}{*}{ Caso } & \multirow[t]{2}{*}{ Categoria } & \multirow[t]{2}{*}{ Sexo, idade } & \multirow{2}{*}{$\begin{array}{l}\text { Títulos Ac } \\
\text { mães (HI) }\end{array}$} & \multirow[t]{2}{*}{ Órgãos examinados ${ }^{\mathrm{a}}$} & \multirow[t]{2}{*}{ Alterações histopatológicas (HE) } & \multicolumn{2}{|c|}{ Testes para $T$. gondii } \\
\hline & & & & & & IHQ & Nested-PCR \\
\hline 1 & Neonato & Macho, 8 dias & $1: 2048$ & CE, C, R, T, F, LN, P, MM, B. & $\begin{array}{l}\text { Encefalite não supurativa e malácia multifocal, } \\
\text { miocardite mononuclear, nefrite intersticial mononu- } \\
\text { clear multifocal, hepatite periportal mononuclear, } \\
\text { linfadenite granulomatosa multifocal e pneumonia } \\
\text { intersticial piogranulomatosa difusa }\end{array}$ & + & Não realizado \\
\hline 2 & Natimorto & Macho, $\mathrm{Nd}^{\mathrm{b}}$ & $1: 2048$ & CE, ME, C, MM, T, P, R. & Mielite não supurativa multifocal & - & + \\
\hline 3 & Natimorto & Fêmea, Nd & $1: 2048$ & CE, F, C, P, MM, R, T, B. & $\begin{array}{l}\text { Encefalite não supurativa e malácia multifocal e pneu- } \\
\text { monia intersticial mononuclear difusa }\end{array}$ & - & + \\
\hline 4 & Natimorto & Macho, Nd & $1: 512$ & CE, R, F, C, ME, MM, B. & $\begin{array}{l}\text { Encefalite não supurativa e malácia multifocal, pneu- } \\
\text { monia intersticial mononuclear difusa e necrose de } \\
\text { folículos linfóides do baço }\end{array}$ & - & + \\
\hline 5 & Neonato & Macho, 3 dias & $1: 2048$ & CE, ME, P, R, MM, T, B e C. & $\begin{array}{l}\text { Meningoencefalite não supurativa multifocal e me- } \\
\text { ningite não supurativa focalmente extensa }\end{array}$ & - & + \\
\hline 6 & Aborto* & $\begin{array}{l}\mathrm{Nd}, 3 \text { fetos } \\
\text { mumificados }\end{array}$ & $1: 2048$ & CE, F, R, PL e P. & Gliose multifocal & - & + \\
\hline
\end{tabular}

a $\mathrm{CE}=$ cérebro, $\mathrm{C}=$ coração, $\mathrm{R}=$ rim, $\mathrm{T}=$ timo, $\mathrm{F}=$ fígado, $\mathrm{LN}=$ linfonodo mesentérico, $\mathrm{P}=$ pulmão, $\mathrm{MM}=$ músculo esquelético, $\mathrm{B}=$ baço, $\mathrm{ME}=$ medula espinhal, $\mathrm{PL}=$ placenta, ${ }^{\mathrm{b}} \mathrm{Nd}=\mathrm{Não}$ determinada. 


\section{DISCUSSÃO}

Abortos por Toxoplasma gondii têm distribuição mundial e taxas de prevalência que variam de 6.4- 27.2\% (Bekele \& Kasali 1989, Chanton-Greutmann et al. 2002, Masala et al. 2003, Sharma et al. 2003). Quadros clínico-patológicos diversos têm sido associados com a doença (Burridge 1980). Entretanto, perdas reprodutivas tais como morte embrionária, morte fetal, mumificação, aborto, natimortalidade e morte neonatal são os achados mais comuns (Blewett 1983, McSporran et al. 1985), tendo sido também nesse estudo os achados clínicos observados. Os achados clínicos, macroscópicos, histopatológicos, sorológicos, imunoistoquímicos e moleculares foram característicos da infecção por Toxoplasma gondii. Em geral, lesões em tecidos fetais são achados microscópicos, particularmente observadas no cérebro, fígado e pulmão (Hartley \& Kater 1963, Beverley et al. 1971, Dubey \& Beattie 1988). Encefalite não supurativa e gliose multifocal têm sido freqüentemente descritas nas perdas por Toxoplasma sp. (Munday \& Mason 1979, Dubey \& Bettie 1988, Buxton 1991), o que também foi confirmado aqui. Áreas branco-amareladas com cerca de $2 \mathrm{~mm}$ de diâmetro nos cotilédones da placenta (Hartley \& Kater 1963, Beverley et al. 1971), microscopicamente correspondentes a áreas de necrose e mineralização, também têm sido descritas (Dubey 1980). Tais achados não foram confirmados, pois nenhuma alteração foi observada em apenas uma placenta enviada para diagnóstico. Animais jovens, imunodeprimidos e com infecção sistêmica por Toxoplasma gondii geralmente desenvolvem pneumonia intersticial, hepatite necrosante focal, linfadenite, miocardite e meningoencefalite não supurativa (Dubey et al. 1987, Hartley \& Dubey 1991, Barker et al. 1992, Reddacliff et al. 1993). Essas alterações foram vistas nos Casos 1 e 5 , ambos neonatos de 8 e 3 dias de idade, respectivamente, e que nasceram fracos e morreram subseqüentemente. Não foram observados cistos de T. gondii nas colorações de hematoxilina-eosina, o que pode estar relacionado à dificuldade de detectar cistos degenerados em colorações histológicas rotineiras (Uggla et al. 1987).

Técnicas sorológicas têm sido implementadas para detectar anticorpos de $T$. gondii em amostras de soro sangüíneo de animais adultos (Wilson et al. 1990, Figueiredo et al. 2001, Massala et al. 2003). A hemaglutinação indireta tem sido o teste mais utilizado devido à rapidez de execução e baixo custo (Chang et al. 1985). Os altos títulos de anticorpos maternos contra $T$. gondii não foram associados com histórico de vacinação, devendo, portanto estarem associados com infeç̧ão. Nesse sentido, a sorologia das mães contribuiu para o diagnóstico da doença no rebanho. A detecção de $T$. gondii nos tecidos fetais foi obtida por imunoistoquímica e nestedPCR em fragmentos de cérebro, fígado e coração. Estudos têm ressaltado a importância da técnica de PCR para o diagnóstico complementar de toxoplasmose, inclusive com potencial para aplicação na rotina. A técnica tem sido intensivamente utilizada por pesquisadores (Lin et al. 2000, Masala et al. 2003, Sreekumar et al. 2004) devido à alta sensibilidade que tem demonstrado em comparação com a imunoistoquímica, aspecto que também foi confirmado nesse relato. As infecções por Sarcocystis sp, Neospora caninum e vírus da CAEV devem ser consideradas no diagnóstico diferencial de Toxoplasma gondii. A infecção por Sarcocystis sp foi descartada, pois os protozoários não foram encontrados no interior de células endoteliais, nem apresentaram formato em roseta, característica morfológica marcante de Sarcocystis sp. A infecção por Neospora caninum em caprinos tem sido esporadicamente descrita (Corbellini et al. 2001), mas também foi descartada pela imunoistoquímica (Dubey 1977). A possibilidade de infecção por CAEV foi considerada em função da malácia que acompanhava a encefalite na maioria dos casos, porém o resultado sorológico negativo em todos os animais do rebanho a excluiu. A forma de infecção desse surto não pode ser determinada, mas a ingestão de oocistos de $T$. gondii que passa a ser liberado nas fezes de gatos é considerada a principal fonte de infecção (Dubey \& Bettie 1988) e, pelo menos dois gatos eram mantidos na propriedade. Em consequiência dos resultados observados, ressalta-se a necessidade de incluir Toxoplasma gondii entre as causas de perdas reprodutivas em caprinos no Brasil.

Agradecimentos.- À Professora Ana Paula Ravazzolo, do Laboratório de Virologia da Faculdade de Veterinária, UFRGS, pelos exames para vírus da Artrite e Encefalite Caprina e à Dra. Rovaina L. Doyle, do Laboratório de Sorologia do Centro de Pesquisa Veterinária Desidério Finamor (CPVDF) pela realização dos testes de hemaglutinação indireta para Toxoplasma gondii. Este estudo foi financiado pela CAPES e pelo CNPq.

\section{REFERÊNCIAS}

Alton G.G., Jones L.M., Angus R.D. \& Verger J.M.1998. Techniques for the Bucellosis Laboratory. Institut Nacional de la Recherche Agronomique, Paris, p.169-174.

Amaral V., Santos S.M. \& Rebouças M.M. 1978. Sobre a prevalência de anticorpos anti-toxoplasma em soros de caprinos e ovinos procedentes respectivamente dos Estados da Bahia e Rio Grande do Sul. Biológico 44:331-340.

Barker I.K., Druemel A.A. \& Palmer N. 1992. The alimentary system, p.1- 308. In: Jubb K.V.C., Kennedy P.C. \& Palmer, N. (ed.), Pathology of Domestic Animals. Vol.2. 4th ed. Academic Press, San Diego. 747p.

Bekele T. \& Kasali O.B. 1989. Toxoplasmosis in sheep, goats and cattle in central Ethiopia. Vet. Res. Commun. 13:371-375.

Beverley J.K.A., Watson W.A. \& Spence, J.B. 1971. The pathology of the foetus in ovine abortion due to toxoplasmosis. Vet. Rec. 88:174-178.

Blewett D.A. 1983. The epidemiology of ovine toxoplasmosis. I. The interpretation of data for the prevalence of antibody in sheep and other host species. Brit. Vet. J. 139:537-545.

Blewett D.A. \& Watson W.A. 1984. The epidemiology of ovine toxoplasmosis. III. Observations on outbreaks of clinical toxoplasmosis in relation to possible mechanisms of transmission. Brit. Vet. J. 140:54-63.

Borde G., Lowhar G. \& Adesiyun A. 2006. Toxoplasma gondii and Chlamydophila abortus in caprine abortions in Tobago: a sero-epidmiological study. J. Vet. Med. B. 53(4):188-194.

Burridge J.J. 1980. Toxoplasmosis. Compend. Contin. Educ. Vet. Pract. 5:456462.

Buxton D. 1991. Toxoplasmosis, p.49-58. Martin W.B. \& Aiken I.D. (ed.), Diseases of Sheep. Blackwell Scientific Publications, Oxford.

Chang G.N., Nemzek J.A., Tjostem J.L. \& David A.G. 1985. Simple hemagglutinating inhibition test for the diagnosis of toxoplasmosis. J. Clin. Microbiol. 21(2):180-183.

Chanton-Greutmann H., Thoma R., Corboz L., Lorel N. \& Pospischil A. 2002. Abortion in small ruminants in Switzerland: investigations during two lambing seasons (1996-1998) with special regard to clamydial abortions. Schweiz. Arch. Tierheilkd. 144(9):483-492. 
Chiari C.A., Lima W.S., Lima J.D. \& Antunes C.M.F. 1987. Soro-epidemiologia da toxoplasmose caprina em Minas Gerais, Brasil. Arq. Bras. Med. Vet. Zootec. 39:587-609.

Corbellini L.G., Colodel E.M. \& Driemeier D. 2001. Granulomatous encephalitis in a neurologically impaired goat kid associated with degeneration of Neospora caninum tissue cysts. J. Vet. Diagn. Invest. 13(5):416-419.

Dubey J.P. 1977. Toxoplasma, Hammondia, Besnoitia, Sarcocystis, and Other Tissue Cyst-Forming Coccidia of Man and Animals, p.101-237. Kreier J.P. (ed.), Parasitic Protozoa. Vol.3. Academic Press, New York.

Dubey J.P. 1980. Persistence of encysted Toxoplasma gondii in caprine livers and public health significance of toxoplasmosis in goats. J. Am. Vet. Med. Assoc. 177(12):1203-1207.

Dubey J.P. \& Beattie C.P. 1988. Toxoplasmosis of Animals and Man. Boca Raton, CRC Press, Florida, 220p.

Dubey J.P., Emond J.P., Desmontis G. \& Anderson, W.R. 1987. Serodiagnosis of postnatally and prenatally induced toxoplasmosis in sheep. Am. J. Vet. Res. 48:1239-1243.

Figueiredo J.F., Silva D.A.O., Cabral D.D. \& Mineo, J.R. 2001. Seroprevalence of Toxoplasma gondii infection in goats by the indirect haemagglutination, immunofluorescence and immunoenzimatic tests in the region of Uberlândia, Brazil. Mem. Inst. Oswaldo Cruz 96(5):687-692.

Freyre A., Bonino J., Falcon J., Castells D., Correa D. \& Casaretto A. 1999. The incidence and economic significance of ovine toxoplasmosis in Uruguay. Vet. Parasitol. 81:85-88.

Gondim L.F.P., Barbosa Jr. H.V., Ribeiro Filho C.H.A. \& Saeki H. 1999. Serological survey of antibodies to Toxoplasma gondii in goats, sheep, cattle and water buffaloes in Bahia State, Brazil. Vet. Parasitol. 82:273-276.

Hartley W.J. \& Kater J.G. 1963. The pathology of Toxoplasma infection in the pregnant ewe. Res. Vet. Sci. 4:326-332.

Hartley W.J. \& Dubey J.P. 1991. Fatal toxoplasmosis in some native Australian birds. J. Vet. Diagn. Invest. 3:167-169.

Hurtado A., Aduriz G., Moreno B., Barandika J. \& Garcia-Perez A.L. 2001. Single tube nested PCR for the detection of Toxoplasma gondii in fetal tissues from naturally aborted ewes. Vet. Parasitol. 102:17-27.

Lin M.H., Chen T.C., Kuo T.T., Tseng C.C. \& Tseng C.P. 2000. Real time PCR for quantitative detection of Toxoplasma gondii. J. Clin. Microbiol. 38(11):41214125.

Maciel K.P. \& Araújo F.A.P. 2004. Inquérito sorológico para detecção de anticorpos de Toxoplasma gondii em caprinos (Capra hircus) criados nos municípios de Gravataí e Viamão, região da Grande Porto Alegre, Rio Grande do Sul, Brasil. Revta Ciênc. Agrovet., Lages, 3(2):121-125.
Massala G., Porcu R., Madau L., Tanda A., Ibba B., Satta G. \& Tola S. 2003. Survey of ovine and caprino toxoplasmosis by IFAT and PCR assays in Sardinia Italy. Vet. Parasitol. 117:15-21.

McSporran K.D., McCaughan C., Currall J.H.S. \& Demsteegt A. 1985. Toxoplasmosis in goats. N. Z. Vet. J. 33(3):39-40.

Miller D.A., Wilson M.A. \& Kirkbride C.A. 1989. Evaluation of multivalent Leptospira fluorescent antibody conjugates of general diagnostic use. J. Vet. Diagn. Invest. 1:146-149.

Munday B.L. \& Mason R.W. 1979. Toxoplasmosis as a cause of perinatal deaths in goats. Aust. Vet. J. 55:485-487.

Owen M.R., Clarkson M.J., \& Tree A.J.1998. Diagnosis of toxoplasma abortion in ewes by polymerase chain reaction. Vet. Rec. 25:445-448.

Reddacliff G.L., Hartley W.J., Dubey J.P. \& Cooper D.W. 1993. Pathology of experimentally-induced, acute toxoplasmosis in macropods. Aust. Vet. J. 70:4-6.

Sella M.Z., Navarro I.T., Vidotto O., Freire R.L. \& Shida P.N. 1994. Epidemiologia da toxoplasmose caprina: levantamento sorológico do Toxoplasma gondii em caprinos leiteiro na microrregião de Londrina, Paraná, Brasil. Revta Bras. Parasitol. Vet. 3(1):13-16.

Sharma S.P., Baipoledi E.K., Nyange J.F. \& Tlagae L. 2003. Isolation of Toxoplasma gondii from goats with history of reproductive disorders and the prevalence of toxoplasma and chlamydial antibodies. Onderstepoort J. Vet. Res. 70(1):65-68.

Silva, A.V., Cunha, L.P., Meireles, L.R., Gottschalk, S., Mota, R.A. \& Langoni, H. 2003. Toxoplasmose em ovinos e caprinos: estudo soroepidemiológico em duas regiões do estado de Pernambuco, Brasil. Ciência Rural, Santa Maria, 33(1):115-119.

Skjerve E., Waldeland H., Nesbakken T. \& Kapperund G. 1998. Risk factors for the presence of antibodies to Toxoplasma gondii in Norwegian slaughter lambs. Prev. Vet. Med. 35:219-227.

Sreekumar C., Rao J.R., Mishra A.K., Ray D., Joshi P. \& Singh R.K. 2004. Detection of toxoplasmosis in experimentally infected goats by PCR. Vet. Rec. 154:632-635.

Timoney J.F., Gillespie J.H., Scott F.W. \& Barlough J.E. 1988. Hagan and Bruner's Microbiology and Infectious Disease of Domestic Animals. 8th ed. Cornell University Press, Ithaca. 951p.

Uggla A., Sjoland L. \& Dubey J.P. 1987. Immunohistochemical diagnosis of toxoplasmosis in fetuses and fetal membranes of sheep. Am. J. Vet. Res. 48:348-351.

Wilson M., Ware D.A. \& Juranek D.D. 1990. Serologic aspects of toxoplasmosis. J. Am. Vet. Med. Assoc. 196(2):277-281. 